\title{
Representações da Associação de Agricultura Orgânica sobre a agricultura orgânica
}

\section{Representations of the Organic Agriculture Association on organic farming}

\section{Túlio Luís Borges de Lima}

tuliolimaborges@gmail.com

Mestrando em Extensão Rural pela Universidade Federal de Viçosa (UFV)

\section{Marcelo Leles Romarco de Oliveira}

marcelo.romarco@ufv.br

Doutor em Ciências Sociais em Desenvolvimento, Agricultura e Sociedade pela Universidade Federal Rural do Rio de Janeiro (UFRRJ). Professor do Departamento de Economia Rural na Universidade Federal de Viçosa (UFV)

\section{Sheila Maria Doula}

sheila@ufv.br

Doutorado em Pós Graduação Em Antropologia Social pela Universidade de São Paulo (USP). Professora do Departamento de Economia Rural na Universidade Federal de Viçosa (UFV)

\section{Diana Dias}

dianadiass@gmail.com

Mestranda em Extensão Rural pela Universidade Federal de Viçosa (UFV) 


\title{
RESUMO
}

O objetivo deste trabalho é estudar as representações sociais - apoiado na respectiva teoria - de uma instituição representativa da agricultura orgânica no Brasil - a Associação de Agricultura Orgânica. A metodologia baseia-se numa abordagem qualitativa, tratando-se de um estudo do tipo descritivo-exploratório onde foram aplicados os métodos da revisão bibliográfica e da análise documental. Dentre as conclusões, afirma-se que o imaginário da instituição estudada constituise de diferentes tipologias de agriculturas alternativas mas que se unificam enquanto agricultura orgânica (nós), assim como sua identidade coloca-se, sob diferentes perspectivas, em oposição à Revolução Verde (o outro).

Palavras-chave: Teoria das representações sociais, Revolução Verde, Associação de Agricultura Orgânica, Brasil

\begin{abstract}
The objective of this work is to study the social representations - supported in the respective theory - of a representative institution of organic agriculture in Brazil - the Association of Organic Agriculture. The methodology is based on a qualitative approach, being a descriptive-exploratory study where the methods of bibliographic review and documentary analysis were applied. Among the conclusions, we affirm that the imaginary of the studied institution is constituted of different typologies of alternative agriculture but that they are unified as organic agriculture (nodes), as well as its identity is placed, from different perspectives, in opposition to the Green Revolution (the other).
\end{abstract}

Keywords: Theory of social representations, Green Revolution, Association of Organic Agriculture, Brazil 


\section{Introdução}

Há registros de que a agricultura tenha surgido entre 7000 e 1000 A.C. A partir deste fato histórico, o homem deixa de ser nômade e coletor de alimentos colocando-se como sedentário e agricultor. Assim, com o avançar dos séculos, grandes civilizações baseadas numa agricultura predominantemente às margens de rios, desenvolveram-se apoiadas em sistemas autossuficientes. Foi com base nestes que a civilização foi ganhando seus excedentes, processo que, muitos séculos depois, culmina na modernização da agricultura e a industrialização (Silva \& Junior, 2010).

No século XX, a partir dos anos 1940, norte-americanos embebidos pela confiança exagerada em uma vida melhor apoiada nos grandes avanços da química dão início à Revolução Verde; esta, por meio do discurso de se aumentar a produção de alimentos no mundo, atuou pelo desenvolvimento de um aparato (ou pacote) tecnológico, baseado em uma agricultura adjetivada como moderna. Dentre algumas das tecnologias desenvolvidas à época citam-se sementes de alto rendimento, sistemas de irrigação e mecanização, fertilizantes sintéticos, e agrotóxicos (Bonzi, 2013). No cenário agrícola atual, incluindo o brasileiro, além do aperfeiçoamento, da diversificação e da adoção quase que generalizada destas (Silva \& Junior, 2010), acrescenta-se, dentre outras tecnologias, o desenvolvimento e o uso de organismos geneticamente modificados, em destaque, as sementes transgênicas.

Entretanto, apesar de uma condição de hegemonia na agricultura mundial, desde a sua origem o referido movimento já era questionado. A americana Rachel Carson foi, inclusive, uma das primeiras a fazê-lo. Em seu livro Primavera Silenciosa (1962), dentre várias problematizações, analisa as monoculturas extensivas, as quais, com suas extensões de áreas intermináveis de uma cultura só, aliadas às práticas modernas advindas da Revolução Verde, abdicam dos princípios pelos quais a natureza opera, gerando aumentos explosivos de populações de organismos considerados, nesse contexto, como pragas. Em suas palavras, trata-se de uma agricultura como o engenheiro a concebe, contextualizada em um cenário embebido por processos de uma simplificação que desequilibra.

Corroborando com as ideias da autora, Clay, Chamon \& Rodrigues (2016), ao estudarem trabalhos de Boaventura de Sousa Santos, Mazzeoleni e Nogueira, e Azevedo, analisam como a agricultura mundial foi adquirindo um certo "padrão técnico moderno", iniciado com o desenvolvimento do capitalismo, e trazendo graves consequências sob as 
perspectivas econômica, ambiental e social. "A produção tornou-se padronizada e foi reduzida a um modelo simples e compacto, facilitando seu uso no campo da agricultura" (p. 259), dando significado, portanto, à Revolução Verde. A esta e, por consequência, aos sistemas agrícolas de produção que lhe preconizam, Botton Barcellos (2011), Bernal Cuenca (2011) e Ehlers (1994) atribuem muitos problemas socioambientais. Destes, além de escândalos alimentares alertados por Bernal Cuenca (2011), Ehlers (1994) enumera outros: "a erosão e a perda da fertilidade dos solos; a destruição florestal; a dilapidação do patrimônio genético e da biodiversidade; a contaminação dos solos, da água, dos animais silvestres, do homem, do campo e dos alimentos" (p. 24).

Como alternativa à Revolução Verde, a qual neste trabalho será entendida como sinônimo dos termos agricultura moderna, agricultura convencional ou agricultura industrial, Gliessman (2003) considera a agroecologia, conceituando-a como a aplicação dos conceitos e princípios ecológicos no desenho e manejo de agro ecossistemas sustentáveis. $\mathrm{O}$ autor ainda acrescenta que a agricultura moderna, em certo grau, perdeu sua base ecológica, a qual, diferentemente, pode ser reintroduzida quando de uma perspectiva de sistemas de produção agroecológicos. Além disso, ainda afirma que tais sistemas, devido a suas características de produção de múltiplos produtos, reaproveitamento de resíduos e valorização da diversidade de seres vivos são mais produtivos do que a agricultura convencional.

Para a análise que aqui se propõe é importante destacar que tanto a agricultura moderna quanto a agroecologia têm defensores, praticantes e políticas públicas específicas, constituindo-se em grupos bem definidos em termos de identidades sociais e escalas valorativas que no espaço público se colocam como diferentes, ou seja, em relação "nós" e os "outros" (Todorov, 1993). Também se enfatiza que para a construção de suas identidades, esses grupos recorrem e reivindicam para si memórias e trajetórias históricas distintas, por exemplo, negando ou apoiando a continuidade e os desdobramentos da Revolução Verde. No espaço público essa relação de alteridade fica visível nas narrativas e nos discursos, nos quais memórias partilhadas permitem tanto "pensar-se idêntico no tempo", como provocar a negação, o silenciamento e o esquecimento do "outro" (Candau, 2005).

A legislação brasileira concebe que sistemas de produção agroecológica, biodinâmica, natural, sustentável, regenerativa, biológica e permacultura são todos englobados pelo conceito de sistema orgânico de produção (BRASIL, 1999). Não indo 
ao desencontro com as ideias de Gliessman, mas detalhando-as em maior grau, tal legislação considera um sistema orgânico de produção como:

[...] todo aquele em que se adotam tecnologias que otimizem o uso de recursos naturais e socioeconômicos, respeitando a integridade cultural e tendo por objetivo a auto sustentação no tempo e no espaço, a maximização dos benefícios sociais, a minimização da dependência de energias não renováveis e a eliminação do emprego de agrotóxicos e outros insumos artificiais tóxicos, organismos geneticamente modificados-OGM/transgênicos ou radiações ionizantes em qualquer fase do processo de produção, armazenamento e de consumo [...]. (BRASIL, 1999, p. 11).

Baseadas em Peterson (2012), Clay, Chamon e Rodrigues (2016) reiteram que a agricultura orgânica (AO), dentre as diversas formas alternativas de agricultura anunciadas, é das mais conhecidas, praticadas e detentora de uma história científica bem elucidada. Todavia, é salutar dizer que em virtude do crescimento exponencial de tipologias de agricultura pautadas na Revolução Verde, a AO teve ao longo do tempo sua influência econômica reduzida. Apesar disso, as autoras defendem, dentro do cenário brasileiro, a real possibilidade de associação da $\mathrm{AO}$ à agricultura familiar, assim como a processos artesanais de produção. Interpretando as ideias de Carmo (1998) sobre a agricultura familiar, Silva e Junior (2010) defendem a possibilidade de vislumbrar sua inserção numa política de sustentabilidade ambiental, lembrando que a agricultura moderna é criticada por suas externalidades ambientais negativas.

Entretanto, retomando Clay, Chamon e Rodrigues (2016), ao realizarem uma revisão da literatura nacional das representações sociais sobre alimentos orgânicos pelos agricultores, afirmam ter se construído no imaginário popular "a noção da agricultura familiar como forma arcaica e ineficiente de produção, e a noção de alimentos orgânicos como produtos saudáveis, mas de produção limitada e artesanal e, por isso mesmo, caros e pouco acessíveis" (p. 246). Em oposição a essas representações do imaginário coletivo, concebem que as categorias agricultura familiar e AO devem ser colocadas para além da noção produtivista, já que se relacionam a um cenário bem mais amplo, quer seja, “à saúde da população, ao acesso e à divisão da terra, ao meio ambiente, às desigualdades sociais, aos trabalhadores do campo e ao estado econômico não somente das pessoas envolvidas, mas também do país" (p. 246).

O mesmo estudo detectou um pequeno número de trabalhos, indicando a carência de uma literatura nacional sobre o tema e, consequentemente, uma agenda ainda a ser 
desenvolvida. Além disso, considerando sua importância ante os impactos da $\mathrm{AO}$ e agricultura familiar nacional, estas merecem uma abordagem multidisciplinar, na qual a Teoria das Representações Sociais pode contribuir de forma substantiva (Clay, Chamon \& Rodrigues, 2016).

Ainda nesse contexto, em um estudo francês que buscou construir os conceitos de desenvolvimento sustentável e de agricultura sustentável segundo as representações da imprensa e dos agricultores, sendo todos atores envolvidos com questões de sustentabilidade, Bihannic e Michel-Guillou (2011) observaram uma não unanimidade sobre o conceito de desenvolvimento rural, a qual pode estar relacionada, por conseguinte, à sua representação social, uma vez que cada indivíduo ou grupo tem suas preocupações e interesses, portanto, suas interpretações.

Assim sendo, este trabalho estabelece como seu objetivo estudar as representações sociais de um grupo (ou instituição) envolvido no universo da AO sobre a própria AO. Concordando com Botton Barcellos (2011), concebemos que tal universo, no contexto brasileiro, é complexo e formado por uma enormidade de possíveis grupos de interesse social. Dessa forma, dentre as várias possibilidades de escolha, optamos por adotar como unidade de análise deste estudo a Associação de Agricultura Orgânica (AAO). Assim sendo, hipótese levantada é de que a AO é representada pela AAO como sinônimo de outras tipologias de agricultura e opositora àquela resultante da Revolução Verde, sob diversas perspectivas.

A AAO tem sua origem ligada à construção de um cadastro de pessoas que defendiam a prática de agriculturas alternativas no Brasil, visando, dentre outras coisas, a divulgação do movimento, e que, pouco depois, no ano de 1980, culminou na criação do Grupo de Agricultura Alternativa, o GAA, cujo nome foi escolhido para abranger e abrigar as diversas correntes da época, como agricultura orgânica, biodinâmica, natural e biológica. Dentre os participantes desse grupo estava Ana Maria Primavesi, importante referencial técnico para a consolidação da $\mathrm{AO}$ no país. Com o passar do tempo e a construção de um cenário marcado por disputas políticas, após a expansão dos diálogos para além do estado de São Paulo e uma ampla consulta nacional sobre a viabilidade de uma associação representativa do movimento, em 1989, ou seja, dez anos depois da criação do GAA, este é transformado na AAO. Em seu site, a AAO afirma ter ganhado credibilidade e expressão devido à "postura e ação política e técnico científica fundamentada, independente, crítica, pautada pelo interesse coletivo, e tendo como foco 
central a promoção da agricultura orgânica enquanto alternativa coerente e sustentável em âmbito sócio ambiental" (AAO, 2016a).

Apresentados alguns conceitos caros à contextualização e discussão deste trabalho, passemos ao estudo da Teoria das Representações Sociais, a qual lhe servirá também como importante suporte metodológico.

\section{Teoria das representações sociais}

Apesar de oriunda da parte da sociologia de Durkheim que versa sobre representações coletivas, é na psicologia social que a representação social se teoriza enormemente, tendo sido desenvolvida por Serge Moscovici, na década de 1950; posteriormente aprofundada por Denise Jodelet (Arruda, 2002; Alexandre, 2001).

Conceito, portanto, resgatado por Moscovici, as representações sociais buscam "[...] designar fenômenos múltiplos observados e estudados em termos de complexidades individuais e coletivas ou psicológicas e sociais" (Sêga, 2000, p. 128). Jodelet (2001) ao estudar a teoria do referido psicólogo social, afirma que este renova a análise ao insistir quanto à especificidade dos fenômenos representativos nas sociedades contemporâneas, as quais, a seus olhos, caracterizam-se pela intensidade e fluidez das trocas e comunicações, pelo desenvolvimento da ciência, assim como pela pluralidade e a mobilidade sociais.

Portanto, a Teoria das Representações Sociais, a partir de Moscovici, trabalha com o pensamento social em sua dinâmica e diversidade, partindo da premissa de que existem formas diferentes - guiadas por objetivos distintos - de conhecer e de se comunicar. $\mathrm{O}$ senso comum e a forma científica são duas delas, cada qual gerando seu próprio universo. O universo da primeira seria aquele constituído sobretudo na conversação informal e na vida cotidiana; já o universo da segunda, enquanto tal, existe no espaço científico, com sua linguagem própria e sua hierarquia interna. Destaca-se ainda que as duas formas, apesar de terem fins diferentes, são eficazes e indispensáveis para a vida humana.

Para além, é importante elucidar que as RS se constroem com mais frequência na esfera consensual, na qual, aparentemente não há fronteiras, todos podem falar de tudo. Dito isso, pode-se inferir que Moscovici avança no sentido de reabilitação do senso comum, do saber popular, do conhecimento do cotidiano, anteriormente adjetivado como confuso, inconsistente, equivocado (Arruda, 2002). É nesse sentido que Jodelet (2001) 
aprofunda a teoria moscoviciana, caracterizando as representações sociais como uma forma de conhecimento socialmente elaborada e partilhada, tendo, por sua vez:

[...] um objetivo prático, e que contribui para a construção de uma realidade comum a um conjunto social. Igualmente designada como saber de senso comum ou ainda saber ingênuo, natural, esta forma de conhecimento é diferenciada, entre outras, do conhecimento científico. Entretanto, é tida como um objeto de estudo tão legítimo quanto este devido à sua importância na vida social e à elucidação possibilitadora dos processos cognitivos e das interações sociais. (p. 22)

Ainda sob seu olhar, reconhece as representações sociais como sistemas de interpretação regentes da nossa relação com o mundo e com os outros, além de orientadoras e organizadoras das condutas e das comunicações sociais. As representações sociais, por conseguinte, tornam-se interventoras em muitos processos, dentre eles, “[...] a difusão e a assimilação de conhecimentos, o desenvolvimento individual e coletivo, a definição das identidades pessoais e sociais, a expressão de grupos e as transformações sociais" (Jodelet, 2001, p. 22).

Articulando esses processos, a Teoria das Representações Sociais, por conseguinte, é capaz de contribuir com a formação de identidades coletivas. Para além, de acordo com Pesavento (1994) e Gonçalves (2008), estabelecem-se como um recurso de análise que possibilita apreender as identidades de grupos particulares, a hierarquia de seus valores, assim como suas condutas e formas de coesão social. Tais identidades, portanto, podem ser entendidas como uma partilha do mundo entre pessoas, num contexto de busca de apoio ou de conflito, visando à sua compreensão, sua administração e/ou o seu enfrentamento (Jodelet, 2001).

Pesavento (1994), entremeando-se pela noção de imaginário social, o admite como representação, correspondendo, por sua vez, “[...] à tradução mental, visual e discursiva de uma realidade exterior, vivida, percebida e desejada" (p. 166). Assim sendo, afirma que nem sempre as representações são uniformes, não existindo, ligada a elas, portanto, uma única leitura. Ou seja, "as representações estabelecem seus caminhos de sedução social e convencimento, mas a mensagem veiculada tem leituras diversas, como diversas são as relações entre os atores em cena" (p. 180). 


\section{Metodologia}

A metodologia deste trabalho baseou-se numa abordagem qualitativa. De acordo com Neves (1996), constitui-se em um conjunto de técnicas de interpretação que possibilitam a descrição e a decodificação dos constituintes de um determinado sistema complexo de significados. O universo empírico escolhido foi o site da AAO (2016b), especificamente no que concerne à sua seção "Artigos e Notícias". A amostra de dados correspondeu aos textos publicados na referida seção relativos à agricultura orgânica e a um recorte temporal entre as datas de 21 de outubro de 2015 e 05 de outubro de 2016, num total de 64 .

Apoiando-se na Teoria das Representações Sociais, trata-se de um estudo do tipo descritivo-exploratório onde foram aplicados os métodos da revisão bibliográfica e da análise documental. Sobre esse tipo de análise, Sá Silva, Almeida e Guindani (2009) esclarecem que corresponde a um procedimento que se utiliza de métodos e técnicas para a análise de documentos das mais diversas tipologias. Especificamente, a amostra foi analisada de forma manual, por meio da criação de categorias estabelecidas após uma primeira leitura dos dados.

Com base na riqueza da referida Teoria quanto ao tratamento dos fenômenos representativos, a abordagem apresentada, portanto, partirá de um recorte baseado nos objetos colhidos, os quais, depois de analisados e manipulados, deverão resultar em constructos científicos (Jodelet, 2001). Articulando elementos sócio afetivos e mentais, integrando-os à cognição, à linguagem e à comunicação, e contribuindo para a formação de "identidades coletivas" (Jodelet, 2001), a Teoria das Representações Sociais apresentar-se-á como um recurso analítico apreendedor da identidade de grupos particulares, incluindo, por conseguinte, algumas de suas singularidades (Gonçalves, 2008).

\section{Resultados e discussão}

Sem o intuito de se realizar uma análise de todo o site da AAO, apresenta-se aqui uma breve descrição de sua página principal, a qual encontra-se no endereço $<$ http://aao.org.br/aao/index.php>. Em sua parte superior, à esquerda, é apresentada na cor verde a logomarca da AAO, de onde nota-se a comemoração de seus 28 anos; à direita, por conseguinte, encontram-se dois links, na cor marrom, referentes a duas redes sociais virtuais e a seguinte frase: “interaja com a AAO”. Como plano de fundo a ambos os lados, 
mas com uma abrangência maior no lado direito, encontram-se imagens de alimentos in natura, dentre eles tomate, cebola, pimentão e brócolis.

Imediatamente abaixo da parte superior encontra-se uma série de opções do menu intituladas com termos específicos, escritos em letras brancas e distribuídos numa relativa pequena faixa horizontal, cuja cor de fundo é marrom. Quanto aos termos e seguindo a ordem que são apresentados da esquerda para direita, como links a serem selecionados, tem-se: "Institucional", "Produtores", "Livros", "Publicações", "Cursos", "Artigos e Notícias", "Parceiros", "Vídeos", "Galeria de Fotos", "Agenda do Mês", "Links" e "Contato".

Abaixo da faixa descrita no parágrafo anterior pode-se dividir o espaço virtual em três partes (ou colunas) verticalmente distribuídas. Nessa divisão, as duas colunas laterais ocupam um pouco menos de um terço da largura total da página, logo, a coluna do meio, enquanto tal, abrange praticamente o restante do espaço. Na coluna da esquerda são apresentadas três seções diferentes de menus, as três com palavras escritas em letras brancas e fundo marrom, o qual tem aspecto de tábuas ligadas por cordas. A primeira seção apresenta, dentre outras coisas, o conceito de AO, "experiências exitosas", relatórios e receitas com produtos orgânicos; a segunda seção corresponde às legislações relativas ao universo da $\mathrm{AO}$; por fim, a terceira apresenta a unidade de pesquisa e desenvolvimento em agricultura ecológica da AAO. Abaixo dessas seções, seguem outras duas, intituladas de "espaço cultural" e "serviços", além de links relacionados a diferentes assuntos, dentre eles, a "Campanha permanente contra os agrotóxicos e pela vida", empresas parceiras e mapa de feiras orgânicas.

A coluna da direita, por sua vez, conta com a agenda dos próximos cursos ministrados pela $\mathrm{AAO}$, a qual se apresenta no mesmo formato que as três primeiras seções da coluna oposta, porém com seus caracteres em cor verde e um tamanho menor de fonte. Abaixo, dentre outras opções de menu, segue um espaço de exposição de cartazes relacionados a cursos, uma seção chamada de "Participação institucional", links para sites de instituições parceiras e vídeos relacionados ao tema AO, além de uma seção composta por janela de pesquisa no site, agenda e cadastro eletrônico.

A coluna do meio apresenta um quadro com as últimas atualizações; abaixo deste, um outro trazendo informações e fotos sobre as feiras de "produtor orgânico da AAO", em seguida outros três quadros com fotos e informações sobre três fundadores da AAO. O primeiro deles, de cima para baixo, refere-se a Ana Maria Primavesi, o segundo, a 
Yoshio Tsuzuki; e, o terceiro, a José Lutzenberger. Abaixo destes encontra-se um link, representado por uma espécie de organograma, que leva à seção intitulada de "Visão Sistêmica da Estrutura Funcional Institucional da AAO”.

Por fim, na parte extrema inferior é apresentado o endereço da AAO, assim como um link que leva até um mapa indicador de como se chegar até a sua sede física. Partamos agora à análise do universo empírico, sabendo-se que o mesmo, segundo Arruda (2002 trata-se de “[...] um fenômeno móvel, por vezes volátil, por vezes rígido, cuja complexidade reforça a dificuldade da sua captação. Perceber uma representação social é fácil, mas defini-la, nem tanto.” (p. 138). Dos 64 textos (re)publicados pela AAO e estudados neste trabalho, cerca de $35 \%$ são de autoria da própria AAO; os outros remetem-se a diferentes fontes, como revistas eletrônicas e páginas virtuais de instituições públicas ou privadas, tendo sido direcionados e republicados pela AAO em seu respectivo site, posteriormente à publicação original.

A partir do estudo dos textos foram criadas cinco categorias analíticas, quer seja: "agrotóxicos e sementes transgênicas"; "alimentação e saúde"; "comercialização de alimentos orgânicos"; "AO, instituições, política e legislação"; e, por fim "AO e agroecologia”. Foram estabelecidas porcentagens que relacionam cada categoria com a frequência com que ela apareceu no universo amostral. Todavia, convém esclarecer que tal aparecimento relaciona-se ao assunto principal de cada texto, não impedindo que determinada categoria, digamos que, de maneira secundária, não tenha sido elucidada em um outro texto cujo assunto principal enquadre-se em uma categoria diferente.

No tocante à categoria "agrotóxicos e sementes transgênicas", elencada como assunto principal em $15 \%$ dos textos, os agrotóxicos, anunciados em alguns deles como sinônimo de "veneno" e/ou "pesticidas" foram representados majoritariamente como agressivos à saúde humana e ao meio ambiente, o que corrobora com Carson (1969), que além de posicioná-los como aliados da Revolução Verde e inimigos da natureza, conceitua-os como pesticidas e os denuncia como responsáveis pelo "silêncio" da vida, envenenando não apenas pássaros, mas os seres vivos em geral. Termos como "venenos agrícolas", "agroquímicos", "defensivos", pouco apareceram. Especificamente, o termo "defensivo" foi utilizado em apenas um artigo.

Houve destaque para o fato de a agricultura do Brasil basear-se no uso extensivo de agrotóxicos e, justamente por isso, boa parte dos textos coloca como alarmante o título brasileiro de maior consumidor de agrotóxicos do mundo. Ligado a essa ideia de alarme, 
os agrotóxicos foram, como já dito em relação à Rachel Carson, frequentemente relacionados i) à contaminação ambiental do solo, da água, do ar, dos animais, das plantas, dos alimentos e do homem (incluindo o leite materno); ii) a problemas crônicos de saúde humana, como malformações, abortos, infertilidade, além da incidência de cânceres, depressão, doenças degenerativas e mortes.

Alguns textos problematizaram a temática dos agrotóxicos com a legislação brasileira, a qual, além de permitir o uso de alguns deles que são proibidos em outros países, isenta tais produtos de impostos. Nesse sentido, observou-se expressões questionadoras do rigor e responsabilidade da nossa legislação, representando-a como frouxa e desatualizada.

Outra contestação em relação ao uso do agrotóxico perpassa pelo princípio de simplificação da agricultura que ele carrega consigo, opondo-se à diversidade das áreas tropicais, apresentada como algo construído pela natureza em milhões de anos e podendo ser extrapolada para a representação dos sistemas de produção destacados nos textos, o que será discutido mais à frente. Aliando-se, portanto, às noções de monocultura e transgênicos, registra-se a representação simplista de que quem usa agrotóxico combate o efeito, não a causa. Sobre a implicação dos agrotóxicos e a representação do tempo da natureza, esta pode também ser verificada em Carson (1969): "Para que a vida se ajustasse a estas substâncias químicas, seria necessário tempo, numa escala que é apenas da Natureza, requerer-se-iam não somente os anos da vida de um homem, mas também da vida de gerações" (p. 16). Nesse debate, portanto, tornam-se perceptíveis as representações diferenciadas sobre o tempo e a memória e como essa relação afeta diferentes opções de agricultura; assim, há no mesmo discurso a referência a uma natureza criada no passado imemorial e outra, transformada negativamente por processos históricos e tecnológicos recentes.

As sementes transgênicas são representadas como propiciadoras do aumento do uso de agrotóxicos, da perda e contaminação da biodiversidade de sementes, da exclusão de pequenos agricultores e como recursos não renováveis. Representadas opostamente a essas sementes, sob um viés de valorização positiva, foram identificadas as sementes crioulas. Como alimentos, os transgênicos foram vistos como possíveis causadores de problemas de saúde ainda não conhecidos, quer seja, tóxicos. Para além, a tecnologia que os produz, no caso a transgenia, foi colocada como um "atalho", remetendo-se outra vez à ideia de simplificação da agricultura. Sobre esse processo de simplificação, também 
identificado por Carson (1969), a autora adverte que a “[...] Natureza introduziu grande variedade na paisagem; mas o homem vem acusando inclinação para simplificá-la. Assim, o Homem desfaz os controles e os equilíbrios intrínsecos, por meio dos quais a Natureza mantém as espécies dentro de determinados limites" (p. 20).

Quanto à categoria “alimentação e saúde", assunto principal em 9\% do universo amostral, os conteúdos representacionais mais frequentemente encontrados partem da ideia de que a saúde, vista de uma forma integral, depende da alimentação. A representação do que é uma alimentação saudável perpassa pela possibilidade de saber o que se está comendo e de se interessar pelos impactos da alimentação na própria vida e no mundo. Nessa perspectiva, assim como encontrado no trabalho de Clay, Chamon e Rodrigues (2016), a AO é tida como uma produtora de alimentos saudáveis, de melhor sabor, mais naturais e mais nutritivos, sem produtos químicos ou hormônios, alimentos de verdade e de qualidade; enquanto que, por outro lado, certos alimentos já têm comprovação científica de seus efeitos nocivos à saúde, como foi colocado o caso dos alimentos relacionados a agrotóxicos, transgênicos e ultra processamento, os quais, segundo Carson (1969), dificilmente estariam livres de qualquer resíduo.

Todavia, o imaginário construído expressa que consumir alimentos orgânicos vai além da ideia de se alimentar e de se nutrir, tal ação expande-se para uma postura ecológica, social e econômica, uma vez que, além da negação do consumo de alimentos transgênicos e/ou produzidos com agrotóxicos, contribui para uma produção familiar sustentável e preservadora da natureza, adquirida num contexto de comercialização sem atravessadores. Para além, o consumo de alimentos orgânicos também é representado como uma escolha política entre modelos de produção diferentes, em disputa e coexistentes no campo; em que, cada um, conforme Todorov (1993), com sua identidade. O modelo da AO, por sua vez, assume posição contrária aos agrotóxicos e transgênicos, reverberando a falsa ideia de que a Revolução Verde veio para acabar com a fome no mundo e resolver os problemas da agricultura.

Os alimentos orgânicos exigem de quem os consome uma certa mudança de mentalidade e comportamento, sobretudo no que diz respeito à sua disponibilidade ao longo de todo o ano, ou seja, quem pretende consumir alimentos desse tipo sujeita-se à sazonalidade; além disso, muda-se também, no sentido de se ampliar a diversidade de alimentos consumidos. Assim sendo, a descoberta de "novos" alimentos, muitos deles antes vistos como plantas daninhas e que, conceitualmente deveriam ser eliminadas, na 
realidade, tratam-se de plantas alimentícias não convencionais esquecidas ao longo do tempo. Assim como colocada e baseando-se em Candau (2005), tal situação pode ser atestada como um esquecimento coletivo, um abandono, mas que se encontra num processo de redescoberta, voltando a fazer parte de uma memória compartilhada.

A categoria "comercialização de alimentos orgânicos", verificada como temática principal em $14 \%$ dos textos amostrados, está comumente ilustrada pelos termos "certificação", "expansão", "caros", "venda direta" e "PNAE". A certificação, corroborando com o previsto na legislação orgânica quanto à necessidade de se assegurar a transparência em todos os estágios da produção e da transformação (BRASIL, 1999), é representada como essencial ao comércio dos produtos, o qual é indicado como crescente, sobretudo nas feiras oficialmente orgânicas e nas compras governamentais, como o Programa Nacional de Alimentação Escolar (PNAE). Junto ao termo "certificação", aprecem "comprovação de origem", "garantia" e "segurança". Logo, a certificação, por meio de selos, logomarcas e documentos que lhe são intrínsecos, pode ser considerada, no contexto da Teoria das Representações Sociais, como um símbolo da AO. Voltando às feiras orgânicas, também identificadas como sinônimo de feiras agroecológicas, os conteúdos representacionais as consideram como uma releitura das feiras convencionais. Da mesma forma, a AO é simbolizada como opositiva à agricultura convencional.

Em oposição ao imaginário popular apresentado por Clay, Chamon e Rodrigues (2016) de que produtos orgânicos, apesar de saudáveis, são caros e restritos a elites socioeconômicas, as representações demarcadas nesta categoria indicam um esforço da AAO em desmistificá-lo, sobretudo remetendo-se à ideia de que se tratam de produtos mais saudáveis, adquiridos diretamente de quem os produz, sem a ação de intermediários ou atravessadores e que devem ser popularizados. Assim sendo, apenas os alimentos orgânicos de grandes redes de supermercados são representados como caros e pouco acessíveis e, de maneira oposta, aqueles advindos de compras diretas, seja de feiras ou mesmo adquiridos na propriedade, representam-se como não caros, quer seja, detentores de preço justo e acessível. Especificamente, as feiras podem ser entendidas como importantes equipamentos públicos de abastecimento alimentar.

No tocante à categoria "AO, instituições, política e legislação" (12\%) buscou-se elencar os atores sociais e as representações relacionadas a ações e arranjos, pode-se dizer, interinstitucionais e político-legislativos em direção ao desenvolvimento da AO, como a assinatura de protocolo, elaboração de leis e políticas públicas, construção de parcerias, 
realização de eventos científicos. Diferentes instituições são citadas nos textos e apresentadas em diferentes arranjos institucionais, a maioria deles concentrados em ações constantes em universos da comercialização de produtos orgânicos, da divulgação e a expansão da AO como modelo sustentável de agricultura, da extinção do uso de agrotóxicos e de transgênicos, da alimentação nas escolas, dentre outros. Como instituições, frequentemente apareceram a própria AAO, prefeituras, secretarias municipais (com destaque para aquelas do estado de São Paulo, uma vez que se trata da cidade onde nasce a AAO), outras associações de agricultores orgânicos, universidades, comunidade escolar e seus conselhos, sindicatos, movimentos sociais, organizações não governamentais e associações de bairro. Esses arranjos envolvem-se também na ideia de potencialização de alguns processos em detrimento de outros, como a produção orgânica em relação à agricultura convencional; o consumo sustentável em relação ao desperdício de alimentos; e, inclusive, a conversão integral da alimentação escolar convencional em orgânica, representada como uma "revolução alimentar". Assim, a menção a essas instituições contribui para reforçar a imagem de um "nós", de um coletivo em expansão e de uma rede composta por diferentes atores sociais que passam a compartilhar de uma mesa identidade, principalmente na esfera alimentar.

A última categoria criada é "AO e agroecologia", a qual foi tema principal de 50\% dos textos constituintes da amostra. Essas duas tipologias de agricultura foram representadas como sinônimos, em concordância, portanto com a legislação brasileira (Brasil, 1999), e justamente as que apareceram em maior frequência. Os termos agricultura biodinâmica, agricultura natural, agricultura sintrópica e agricultura de base ecológica também aparecerem com o mesmo significado dos outros dois, entretanto em poucos textos. Pelo conteúdo analisado, independentemente da frequência e, concordando com Carson (1969), Bonzi (2013), Ehlers (1994) e Gliessman (2006), todas essas tipologias de agricultura foram inseridas em seus respectivos contextos como alternativas, ou ainda conforme Todorov (1993), identidades, opositoras às tipologias de agriculturas resultantes da Revolução Verde.

Dentre estas, agricultura convencional, agricultura moderna e agricultura industrial foram as que apareceram nos textos analisados como contraste e oposição. Nestes, essas tipologias foram elucidadas, dentre outras representações, como uma agricultura baseada em técnicas reducionistas e dissociadas do seu meio, fortemente causadora de externalidades negativas. A monocultura, representada como modelo 
simplificado e pouco eficiente sob o ponto de vista energético e no que concerne ao consumo de recursos naturais, ao lado dos insumos externos, dentre eles, destaque para os agrotóxicos e os transgênicos, são seus símbolos mais relevantes.

Continuando na análise simbólica, uma das principais personalidades no meio da $\mathrm{AO}$, não apenas por constar na página principal do site da $\mathrm{AAO}$, mas também nos textos analisados, Ana Primavesi é representada como, além de descobridora dos segredos e da riqueza do solo, um baluarte da ciência agroecológica e vanguardista em um tempo em que não se refletia sobre agroecologia. Seu livro "Manejo ecológico do solo: a agricultura em regiões tropicais" é simbolicamente considerado como a bíblia da agroecologia.

No site aqui estudado, alguns textos constituem-se em reportagens sobre processos de transição agroecológica ou conversão orgânica de famílias de agricultores familiares orgânicos. Apesar de diferentes entre si, algumas semelhanças são verificadas nos referidos processos. Em todos eles, pós 1970, verifica-se que as famílias, algumas já agricultoras antes da Revolução Verde e, portanto, podendo ser consideradas praticantes da produção orgânica, compartilham, com base em Candau (2005), a memória coletiva sobre si enquanto reféns dos insumos externos e, com o passar do tempo, como vítimas de um processo duplo, simultâneo e antagônico de diminuição da produção da propriedade e aumento no consumo de insumos externos. Estes insumos, conforme citados por Bonzi (2013) e dos quais fazem parte os agrotóxicos, correspondiam e ainda correspondem ao pacote tecnológico da Revolução Verde.

Em referência à agricultura familiar, cabe uma análise breve sobre a sua relação com a AO, concordando com Carmo (1998, citado por Silva \& Junior, 2010), que afirma que, entre outros fatores, devido a características intrínsecas dessa categoria social, como a produção diversificada, o cultivo de várias espécies, além da integração agricultura e pecuária, ela é representativa da perspectiva da $\mathrm{AO}$ defendida pela AAO.

\section{Conclusões}

O fenômeno da Revolução Verde, no que concerne à sua presença na agricultura mundial, perpassa por uma ideia de hegemonia, apoiada em uma perspectiva produtivista intencionada a acabar com a fome no mundo e em seu moderno pacote tecnológico. Entretanto, quando olhado por lentes diferentes, num contexto que relaciona um leque maior de perspectivas - econômica, ambiental e social - às suas externalidades negativas, a condição hegemônica de tal fenômeno é questionada. 
Considerando-se esse cenário de questionamento à Revolução Verde, certos processos de criação ou de ressurgimento de tipologias de agriculturas alternativas foram revelados. Dentre estas, com base ao que foi apresentado neste trabalho, pode-se afirmar que agricultura orgânica se coloca como destaque do imaginário sobre agricultura da AAO, além de fazer parte de sua identidade, assim como de sua memória coletiva.

Claramente em oposição à Revolução Verde, diferentes representações sociais sobre técnicas/práticas/princípios/denominações constituintes da constelação do termo "agricultura orgânica" foram evidenciadas, dentre as quais: produção agroecológica em agrofloresta com convívio pacífico e colaborativo entre natureza e a produção de alimentos; diversidade de espécies em equilíbrio natural; plantas bem nutridas com capacidade de cura e defesa contra pragas; diversidade de plantas; diversidade de alimentos; sistema de produção orgânica muito mais amplo do que simplesmente não se usar agrotóxicos; propriedade como um sistema vivo e natural; uso de sementes crioulas; saber popular; sementes crioulas como tradução do conhecimento acumulado; recuperação e conservação dos solos, da água, da vegetação nativa; valorização da mulher e do homem do campo; geração de trabalho e renda; saúde das pessoas que produzem e consomem. Com base nisso e corroborando com Gliessman (2003), confirma-se a representação de que a AO, interpretada com base em Todorov (1993) como "nós", combina discursivamente todos os atributos de positividade, que fazem dela mais produtiva e mais justa socialmente que a agricultura convencional, "o outro".

Todavia, comparando-as ao texto da instrução normativa $\mathrm{n}^{\circ} 007$ de 17 de maio de 1999, pode-se afirmar que entre essas constelações, a preservação da saúde ambiental e humana é privilegiada (BRASIL, 1999), além de irem ao encontro do entendimento de Gliessman (2003) a respeito de uma agricultura sustentável, tratando-se de “(...) uma agricultura que protege a base de recursos naturais, permite uma economia viável e propõe um aspecto social justo e aberto a todos que fazem parte da sociedade" (s.p.). É em suas diferenças, portanto, que esses conteúdos representacionais podem se confirmar como constituintes do universo representacional da $\mathrm{AO}$ sob a perspectiva da AAO.

Remetendo-se à hipótese levantada, pode-se inferir que o imaginário da AAO se constitui de uma série de diferentes tipologias de agriculturas alternativas àquela representada pela Revolução Verde. Além disso, com base nas representações da AAO contra o uso de agrotóxicos e transgênicos; a favor do consumo de alimentos orgânicos, tidos como mais saudáveis e a um preço justo; dos benefícios da compra direta; da 
convergência entre agricultura familiar e AO; e da $\mathrm{AO}$ como uma tipologia de agricultura coerente e sustentável, infere-se que esta identidade, tal como construída nos discursos textuais, unifica as diferentes tipologias de agriculturas alternativas no termo AO (nós); e evidencia sua oposição na forma de crítica à agricultura advinda da Revolução Verde (o outro). A referência ao "outro", portanto, acaba sendo imprescindível para a definição do contraste, para o efeito de comparação e para a persuasão, própria das interações sociais no espaço público, de que a escala de valores da $\mathrm{AO}$ é melhor em todos os sentidos.

\section{Referências bibliográficas}

ALEXANDRE, M. O papel da mídia na difusão das representações sociais. Comum, Rio de Janeiro, v. 6, n. 17, p. 111-125, Jul./Dez. 2001.

ARRUDA, A. Teoria das representações sociais e teorias de gênero. Cadernos de Pesquisa, São Paulo, n. 117, p. 127-147, Nov. 2002.

ASSOCIAÇÃO DE AGRICULTURA ORGÂNICA - AAO. Quem somos - A criação da Associação de Agricultura Orgânica, 2016a.

Artigos e Notícias, $2016 \mathrm{~b}$.

BERNAL CUENCA, E. Comparación socioeconómica de las empresas agrarias de producción ecológica y convencional en Aragón, España: Problemas y oportunidades. Mundo agrário, La Plata, v. 11, n. 22, jun. 2011.

BIHANNIC, L.; MICHEL-GUILLOU, É. Développement durable et agriculture durable: sens du concept de "durabilité" à travers la presse régionale et le discours des agriculteurs. Développement durable et territoires, Vol. 2, n. 3, dez. 2011.

BONZI, R. S. Meio século de Primavera Silenciosa: um livro que mudou o mundo. Desenvolvimento e Meio Ambiente. Editora UFPR, n. 28, p. 207-215, jul./dez. 2013. Editora UFPR.

BOTTON BARCELLOS, S. Mundo agrário, La Plata, v. 12, n. 23, dic. 2011.

BRASIL. Instrução Normativa n. 007 de 17 de maio de 1999. Estabelece normas para produção de produtos orgânicos vegetais e animais. Diário Oficial da União, Brasília, n. 94, Seção 1, p. 11 19, Maio 1999.

CANDAU, J. Antropologia da memória. Instituto Piaget. Lisboa, 2005.

CARSON, R. Primavera Silenciosa. Editora Pórtico. 2ª edição. São Paulo, 1969.

CLAY, E.; CHAMON, E. M. Q. de O.; RODRIGUES, A. M. Representações sociais dos alimentos orgânicos para agricultores - uma revisão da literatura nacional. Desenvolvimento em Questão. Editora Unijuí, ano 14, n. 35, jul./set., 2016. 
EHLERS, E. M. O que se entende por agricultura sustentável? Dissertação (Mestrado em Ciência Ambiental) - Universidade de São Paulo, São Paulo, 1994.

GLIESSMAN, S. R. A agricultura pode ser sustentável. EMATER/RS, Rio Grande do Sul, 2003. Entrevista concedida a Ângela Felippi.

GONCALVES, H. S. et al. Problemas da juventude e seus enfrentamentos: um estudo de representações sociais. Psicologia e Sociedade, Porto Alegre, v. 20, n. 2, p. 217-225, Ago. 2008.

JODELET, D. Representações sociais: um domínio em expansão. In: JODELET, D. (Org.). As representações sociais. Rio de Janeiro: EdUERJ, 2001. p. 17- 44.

NEVES, J. L. Pesquisa qualitativa: características, usos e possibilidades. Caderno de Pesquisas em Administração, São Paulo, v. 1, n. 3, p. 1-5, 2º Sem.1996.

PESAVENTO, S. Trabalhadores e máquinas: representações do progresso (Brasil: 1880-1920). Anos 90, Porto Alegre, v. 2, n. 2, 1994.

SÁ-SILVA, J. R.; ALMEIDA, C. D. de; GUINDANI, J. F. Pesquisa documental: pistas teóricas e metodológicas. Revista Brasileira de História \& Ciências Sociais, São Leopoldo, ano I, n. I, Jul. 2009.

SÊGA, R. A. O conceito de representação social nas obras de Denise Jodelet e Serge Moscovici. Anos 90, Porto Alegre, v. 8, n. 13, Jul. 2000.

SILVA, A. J. da; JUNIOR, M. F. S. Representações sociais e agricultura familiar: indícios de práticas agrícolas sustentáveis no Vale do Bananal - Salinas, Minas Gerais. Sociedade e Natureza. Uberlândia, v. 22, n. 3, p. 525-538, Dez. 2010.

TODOROV, T. A Conquista da América - a Questão do Outro. Martins Fontes. São Paulo,1993. 